\title{
Peripheral and Central Effects of Melatonin on Blood Pressure Regulation
}

\section{Olga Pechanova ${ }^{1,2, *}$, Ludovit Paulis ${ }^{1,3}$ and Fedor Simko ${ }^{3,4,5}$}

1 Institute of Normal and Pathological Physiology and Centre of Excellence for Nitric Oxide Research, Slovak Academy of Sciences, Bratislava 81371, Slovak Republic; E-Mail: ludo@lfuk.sk

2 Department of Animal Physiology and Ethology, Faculty of Natural Sciences, Comenius University, Bratislava 81371, Slovak Republic

3 Department of Pathophysiology, Faculty of Medicine, Comenius University, Bratislava 81371, Slovak Republic; E-Mail: fedor.simko@fmed.uniba.sk

4 The Third Clinic of Internal Medicine, Faculty of Medicine, Comenius University, Bratislava 81371, Slovak Republic

5 Institute of Experimental Endocrinology, Slovak Academy of Sciences, Bratislava 81371, Slovak Republic

* Author to whom correspondence should be addressed; E-Mail: olga.pechanova@savba.sk; Tel.: +421-232-296-020.

External Editor: Rudiger Hardeland

Received: 3 July 2014; in revised form: 17 September 2014 / Accepted: 17 September 2014 / Published: 8 October 2014

\begin{abstract}
The pineal hormone, melatonin ( $N$-acetyl-5-methoxytryptamine), shows potent receptor-dependent and -independent actions, which participate in blood pressure regulation. The antihypertensive effect of melatonin was demonstrated in experimental and clinical hypertension. Receptor-dependent effects are mediated predominantly through MT1 and MT2 G-protein coupled receptors. The pleiotropic receptor-independent effects of melatonin with a possible impact on blood pressure involve the reactive oxygen species (ROS) scavenging nature, activation and over-expression of several antioxidant enzymes or their protection from oxidative damage and the ability to increase the efficiency of the mitochondrial electron transport chain. Besides the interaction with the vascular system, this indolamine may exert part of its antihypertensive action through its interaction with the central nervous system (CNS). The imbalance between the sympathetic and parasympathetic vegetative system is an important pathophysiological disorder and
\end{abstract}


therapeutic target in hypertension. Melatonin is protective in CNS on several different levels: It reduces free radical burden, improves endothelial dysfunction, reduces inflammation and shifts the balance between the sympathetic and parasympathetic system in favor of the parasympathetic system. The increased level of serum melatonin observed in some types of hypertension may be a counter-regulatory adaptive mechanism against the sympathetic overstimulation. Since melatonin acts favorably on different levels of hypertension, including organ protection and with minimal side effects, it could become regularly involved in the struggle against this widespread cardiovascular pathology.

Keywords: melatonin; hypertension; central nervous system (CNS); MT1 and MT2 receptors; reactive oxygen species (ROS)

\section{Introduction}

Essential hypertension is a complex hemodynamic and structural disorder, whose underlying mechanisms involve several familiar pathogenic factors. Genetic background, renal alteration, neurohumoral imbalance or endothelial dysfunction are generally accepted participating factors in hypertension development and progression. Besides peripheral alteration, also central nervous system disorders are involved. Thus, the term neurogenic hypertension was suggested, involving the imbalance between sympathetic and parasympathetic components on the base of the disturbed interplay on the level of the central and peripheral autonomic nervous system [1,2]. Recently, it has been suggested that the inflammation in the brainstem may underlie this neurogenic hemodynamic disorder [2]. Pro-inflammatory molecules, e.g., junctional adhesion molecules, are overexpressed in the endothelium of the microvasculature in the nucleus tractus solitarii, the principal structure controlling arterial blood pressure (BP), with a subsequent leukocyte adherence to inflamed endothelium and inflammatory cytokines release, while this type of inflammatory response seems to be quite specific for the hypertensive brainstem [3]. If the endothelium inflammation in the variable parts of the central nervous system is involved in the pathogenesis of hypertension in a more general way, then substances with a potential anti-inflammatory, antioxidant and endothelium-protecting action in the central nervous system (CNS), such as melatonin, might become important players in the therapeutic targeting.

Melatonin is an endogenous product of the pineal gland, acting as a messenger of the suprachiasmatic nucleus and synchronizing the daily rhythms of variable physiological functions [4-8]. Melatonin plays an important role in the regulation of several parameters of the cardiovascular system [9-11], including blood pressure, and is considered to be a putative antihypertensive agent [12-14]. However, the mechanisms and pathways involved in its BP lowering action are complex and not entirely clear. Both effects, mediated by specific melatonin receptors and direct unspecific actions, particularly those involving the antioxidant nature of melatonin, are of significant biological value. Melatonin and its metabolites $[15,16]$ have extraordinary antioxidant potential and reduce the level of free radical burden on the level of both oxygen and nitrogen species [7,15-17], and their lipophilic action enables them to cross the cell membrane and extend the protective action to all subcellular structures [18-20]. Acting as a direct scavenger, melatonin is able to neutralize different free radicals, such as singlet oxygen, 
superoxide anion radical, hydroperoxide, hydroxyl radical, lipid peroxide radical and highly toxic peroxynitrite anion [21-23]. Indirect antioxidant actions of melatonin reside in the improvement of mitochondrial efficiency [24], stimulation of gene expressions and activation of superoxide dismutase (SOD), catalase and glutathione peroxidase [25]. Furthermore, the ability of melatonin to potentiate the antioxidant action of substances with an antioxidant potential, like glutathione, vitamin $\mathrm{E}$ and vitamin $\mathrm{C}$, may also contribute to better vascular functions and blood pressure regulation [26-28].

\section{Receptor-Dependent Effects of Melatonin on Blood Pressure}

Melatonin receptors influence second messenger cascades that may vary in distinct cell, tissue and species. Specific melatonin receptors were described in the cellular membrane systems, cytosol and even nucleus. Both MT1 and MT2 are membrane-bound G protein-coupled receptors (GPCR). MT1 is primarily linked with Gai and Gaq subunits, while MT2 is mainly connected with Gai [29,30]. The cytosolic MT3 melatonin receptor is actually the quinone reductase 2A, having a low-affinity binding site [31,32]. This enzyme with a supposed effect on the cellular redox state was observed in mammals, but not yet found in humans. Melatonin may directly or indirectly (via MT1) modulate the activity of the nuclear retinoid orphan receptor/retinoid $\mathrm{Z}$ receptor (ROR/RZR), with possible indirect antioxidant effects [30].

The activation of Gai reduces the intracellular level of cAMP, while Gaq stimulation results in phospholipase $\mathrm{C}$ activation, diacylglycerol and inositol-3-phosphate production and increased intracellular $\mathrm{Ca}^{2+}$ levels [33]. The activation of these second messenger cascades in the smooth muscle cells of the peripheral arteries corresponds with the melatonin-induced vasoconstriction observed in the rat caudal artery $[34,35]$. However, it is partly contradictory to the vasodilator effects of melatonin in the mesenteric artery and aorta [36,37]. It was hypothesized that the activation of melatonin receptors on endothelial cells would trigger nitric oxide (NO) formation, whose vasodilatory potential could overwhelm the MT-dependent contraction of smooth muscle cells [38]. Because this process is calcium-dependent, this hypothesis could also provide a rationale for the observed disappearance of the blood pressure reducing effects of melatonin in hypertensive patients controlled by nifedipine [39].

Another possible explanation for melatonin-mediated vasodilation may be Gai-mediated activation of Kir 3 potassium channels [40]. Melatonin-related smooth muscle cell sarcolemma hyperpolarization might reduce the voltage-dependent channel opening and contribute to vasorelaxation [41].

The melatonin receptor subtype distribution in peripheral arteries can significantly influence the biological effect of melatonin. MT1 expression was observed in the rat aorta [42-44], while these receptors were surprisingly localized mainly in the tunica adventitia and not in the smooth muscle and/or endothelial cells [43], and in rat caudal artery [45]. MT2 were observed in porcine coronary arteries [46], in rat caudal artery [45], but not in the aorta [43]. The biological effect of MT1/MT2 stimulation in terms of vascular constriction or dilation may vary in dependence of the particular vessel or the condition of smooth muscle cells layer [45,47].

However, MT receptors may be involved in BP regulation also through the central regulatory mechanisms, since the highest density of melatonin receptors has been shown to be in the central nervous system, particularly in the adenohypophysis [48], suprachiasmatic nucleus (SCN) [49], paraventricular nucleus (PVN) [50] and area postrema [51]. Anyway, although MT1 and MT2 
receptor-melatonin interactions may be of importance, they do not seem to be the major player in the blood pressure regulation by melatonin.

\section{Non-Specific (Receptor-Independent) Actions of Melatonin in Blood Pressure Regulation}

\subsection{Melatonin in $\mathrm{Ca}^{2+}$ Metabolism}

The antioxidative activities of melatonin are considered to be the principal receptor-independent effects of melatonin modulating the blood pressure level. Melatonin's lipophilic nature enables this indolamine to cross the cell membrane and reach subcellular components, including nucleus [52]. The $\mathrm{Ca}^{2+}$-calmodulin complex plays a major role among the intracellular melatonin targets. Nanomolar concentrations of melatonin interact with the $\mathrm{Ca}^{2+}$-calmodulin complex, modifying thusly its effects in many physiological and pathophysiological conditions [53].

The $\mathrm{Ca}^{2+}$-calmodulin interactions with melatonin in the vascular bed result in the modification of intracellular $\mathrm{Ca}^{2+}$ concentrations. While in smooth muscle cells, the melatonin effect on the $\mathrm{Ca}^{2+}$-calmodulin complex may decrease the level of $\mathrm{Ca}^{2+}$ and lead to relaxation, in endothelial cells, the reduced $\mathrm{Ca}^{2+}$ level may inhibit endothelial nitric oxide synthase (NOS), triggering thusly vasoconstriction [54]. Suggestively, the biological effect of the melatonin- $\mathrm{Ca}^{2+}$-calmodulin interplay depends on the type of target cell.

\subsection{Melatonin in the Reduction of Free Radical Burden}

Receptor-independent functions have mostly been discussed in relation to the antioxidant and overall redox-dependent effects of melatonin in experimental models of hypertension [38,55,56-59] and hypertonics $[13,60]$. The antioxidant nature of melatonin involves both direct scavenging of reactive oxygen species (ROS) exerted by high-millimolar concentrations of melatonin or stimulation of the activity and expression of antioxidant enzymes, a response observed at low nanomolar concentrations. Regarding scavenging actions of this indolamine, a potential product of the melatonin interaction with $\mathrm{OH}$ has been identified as cyclic 3-hydroxymelatonin [61,62] with $\mathrm{H}_{2} \mathrm{O}_{2}$ as $N^{1}$-acetyl- $N^{2}$ formyl-5-methoxykynuramine (AFMK) [63], while both 3-hydroxymelatonin and AFMK are effective antioxidants themselves [16,64].

Increased activity and expression of different antioxidant enzymes by melatonin were extensively documented. Long-term melatonin administration (two months) increased catalase activity, leading to the reduction of oxidative stress parameters along with attenuation of hypertension in patients with metabolic syndrome [60], and melatonin administration for 15 days increased SOD-1 activity in elderly hypertonics [65]. It was suggested that melatonin modulates antioxidant enzyme activities via its interaction with calmodulin, which, in turn, inhibits downstream processes inactivating nuclear ROR $\alpha$ receptor, the member of the nuclear (orphan) receptor family, which downregulates $\mathrm{NF}-\kappa \mathrm{B}-$-induced antioxidant enzyme expression [25].

In spontaneously hypertensive rats, melatonin decreased the NF- $\kappa \mathrm{B}$ (p65) expression [55], while the inhibition of NF- $\mathrm{BB}$ pathway in rat endothelial cells reduced lipopolysaccharide-induced NO production [66]. Melatonin seems to interact differentially with the NF- $\mathrm{B}$ pathway, depending 
supposedly on the redox and/or inflammatory state in the particular cardiovascular pathology, including hypertension.

\section{Melatonin and Sympathetic Activity}

The physiology of melatonin is closely bound with the sympathetic nervous system. On the one hand, the melatonin release is controlled by sympathetic afferentation to the pineal gland, mediating the inhibitory effect of light on pineal melatonin secretion [67]. This pathway starts in the retina, influencing the master biological clock in the SCN $[68,69]$. The SCN then inhibits the PVN by $\gamma$-aminobutyric acid (GABA)-ergic innervation [68], leading to interruption of the constant stimulation of the sympathetic intermediolateral nucleus by the PVN [70]. This sympathetic pathway (including interpolation in the superior cervical ganglion) induces the production of melatonin [68] by stimulation of pineal $\beta 1$ - and $\alpha 1$-adrenoceptors [71-73] in rodents or primates, although the actual intracellular mechanism of melatonin production modulation may involve several different ways [74]. Interestingly, the production of melatonin is followed by reduced NF- $\mathrm{KB}$ translocation to the nucleus [75].

On the other hand, melatonin modulates the tone of the autonomic nervous system. Pinealectomized rats showed higher catecholamine levels upon interleukin-1- $\beta$ stimulation, an effect that was abolished by intraventricular infusion of melatonin [76]. In spontaneously hypertensive rats (SHR), acute administration of melatonin reduced blood pressure along with norepinephrine levels [77]. Acute administration of melatonin to normotensive rats reduced blood pressure and heart rate, along with the reduction of serotonin levels in the corpus striatum and hypothalamus [78]. Moreover, in these experiments, the effect of melatonin on blood pressure and heart rate was abolished by spinal transection or bilateral vagotomy, suggesting the involvement of the sympathetic inhibition or parasympathetic stimulation by melatonin [78]. Chronic administration of melatonin (similarly to the antioxidant $N$-acetylcysteine) decreased the blood pressure and heart rate, improved the chronotropic response to isoproterenol, in association with an inhibition of sympathetic activity and the restoration of cardiac $\beta$-adrenoceptor function [79] and improvement of baroreflex [80]. In healthy young men, melatonin reduced the pulsatile index and systolic blood pressure along with norepinephrine levels [81] and reduced blood pressure and pulse wave velocity in association with the attenuation of sympathetic tone [82]. These sympatholytic effects of melatonin may be involved in the blood pressure reducing effect of melatonin seen in SHR [55], $\mathrm{N}^{\mathrm{G}}$-nitro-L-arginine methyl ester (L-NAME) hypertensive rats [56,57], healthy volunteers [81] or patients with essential hypertension [13,29,83,84,], and it also participates in the improvement of insomnia and depression [85].

\section{Melatonin Effects in Central Blood Pressure Regulation}

\subsection{Melatonin Modulation of Central Nervous System (CNS) Sites}

The partly contradictory effects of melatonin on vascular reactivity $[38,86]$, the association of melatonin administration with sympatholytic effects $[79,87]$ and the dependence of melatonin-induced blood pressure decrease on intact spinal cord [78], all suggest a prominent role of the central effects of melatonin on blood pressure regulation. The precise site of this action, however, is still not 
unequivocally elucidated. Previously, several possible sites for the modulation of central nervous system output by melatonin were suggested [38]:

- The activity of the SCN might be modulated by melatonin activity $[69,88]$, reducing thusly the sympathetic tone and providing a protective mechanism against excessive sympathetic excitation.

- In neurons projecting from the SCN to the PVN [70] or in neurons projecting from the caudal ventrolateral medulla (CVLM) to the rostral ventrolateral medulla (RVLM) [89], the GABA-ergic signaling might be potentiated by melatonin [90], either directly or via enhancement of the NO bioavailability [91].

- In the area postrema, which inhibits the activity of RVLM through CVLM [89], melatonin is supposed to modify the epigenetic effect [92].

In addition, in all of these brain targets, melatonin prominent antioxidative nature may participate in the attenuation of the sympathetic tone. Moreover, it has been shown that in stress-induced hypertensive rats, melatonin levels in the anterior hypothalamic area were reduced. A microinjection of melatonin into this site reduced blood pressure along with increased GABA-ergic activity and reduced glutamate-ergic activity in the RVLM. This effect was prevented by MT1/MT2 blockade [93]. Moreover, in this model of hypertension, also chronic intraperitoneal administration of melatonin prevented the increase in blood pressure, whose effect was sensitive to a GABA receptor blockade [94]. On the other hand, the deletion of the SCN abolished circadian blood pressure rhythms, but did not affect absolute blood pressure levels in rats with over-expression of renin [95]. Moreover, periodical administration of melatonin (during the dark phase) did not affect the expression of clock genes or melatonin receptors in the SCN of these rats [96]. It could be suggested that while the action of melatonin on the SCN might interfere with the nocturnal blood pressure level, the effect of melatonin on RVLM (most likely associated with augmented GABA-ergic signaling) may inhibit the sympathetic tone and induce the overall blood pressure reduction independently of the light-dark daily periods.

\subsection{Melatonin, Oxidative Stress and Angiotensin II Interactions}

It is generally admitted that peripheral mechanisms of BP regulation and hypertension treatment are substantially better understood than those at the level of CNS, involving predominantly the relative dominance of sympathetic and renin-angiotensin systems.

Angiotensin II represents a key factor enhancing ROS production in the central nervous system, predominantly by the activation of nicotinamide adenine dinucleotide phosphate (NADPH) oxidase. Besides the cardiovascular system, also the CNS suffers seriously from the long-term impact of the increased reactive oxygen or nitoroso species. The brain is remarkably susceptible to the oxidative stress, because its antioxidant defense is rather poor [28]. In the brain, only the low catalase activity and moderate levels of the antioxidant enzymes, like superoxide dismutase and glutathione peroxidase, were detected. The high levels of iron and ascorbic acid in the brain participate significantly in the catalysis of lipid peroxidation. Additionally, neurotransmitters may be autoxidized, generating thusly ROS [97]. Thus, the antioxidant, scavenging and anti-inflammatory effects of melatonin in the CNS 
may additionally contribute to blood pressure reduction. Melatonin is able to increase the activity and/or mRNA of glutathione peroxidase, copper-zinc superoxide dismutase, manganese superoxide dismutase and reduced glutathione in different brain regions, observed during both acute and chronic treatments with melatonin $[25,98]$. Furthermore, melatonin directly affects the assembly of NADPH oxidase in microglia, potentially through the inhibition of NADPH oxidase phosphorylation via a PI3K/Akt-dependent signaling pathway, blockade of p47(phox) and p67(phox) subunits translocation to the membrane and downregulation of p47(phox) binding to gp91(phox) [99].

Importantly, angiotensin II itself increases melatonin synthesis in the pineal gland [100,101], which may be considered as the self-defending mechanisms restraining the deleterious effects of chronic angiotensin II activation, including hypertension and pathologic remodeling development.

\subsection{Melatonin and Nitric Oxide Interplay}

The relation of melatonin regarding its effect on nitric oxide level is rather complex in the brain tissue. This indolamine and its derivates inhibit neuronal NOS (nNOS) and inducible NOS (iNOS), while the effect on endothelial NOS (eNOS) is less clear. Melatonin inhibits iNOS through the NF- $\kappa$ B-dependent signaling pathway [102-104] and eNOS via modification of the $\mathrm{Ca}^{2+}$-calmodulin complex [105]. nNOS is activated by calcium similarly to eNOS, and an analogic mechanism in the melatonin-nNOS interaction in the brain may be supposed. The study of [106], however, documented that melatonin prevented a decrease of eNOS expression during ischemic brain injury. Thus, it is plausible that the scavenging and antioxidant effect of melatonin may stabilize eNOS and potentially also the nNOS isoform. It seems that the final melatonin effect on different NOS isoforms may vary according to the pathophysiological conditions, dose or strain tested [107]. In any case, the melatonin-nitric oxide pathway interplay at the level of the CNS does not seem to be the crucial factor in BP regulation.

\section{The Potential Role of Melatonin in Nocturnal Blood Pressure Regulation}

Several lines of evidence indicate that disturbed BP rhythmicity-chronodisruption with reduced melatonin secretion is involved in the pathophysiology of nocturnal BP alterations [108].

First, blood pressure undergoes typical circadian rhythmicity with a steep increase in the morning, higher values throughout the active walking period and a deeper decline during nocturnal rest (10\% to $20 \%$ decline of daily values) [109]. Subjects with attenuated BP decline, non-dippers or those with nocturnal hypertension have increased risk of cardiovascular events compared to the common population [110], and nocturnal blood pressure has even been identified as a better predictor of cardiovascular outcome than daily BP values [111]. Most importantly, the shifting of antihypertensive therapy to evening hours not only improved BP control and reduced the number of non-dippers, but remarkably improved the prognosis during the long term, followed up in the MAPEC (Monitorización Ambulatoria para Predicción de Eventos Cardiovasculares/Ambulatory Blood Pressure Monitoring and Events) study [112]. Thus, the chronodisruption of normal BP rhythmicity seems to play a significant role in the prognosis and is an important therapeutic target.

Secondly, it is generally known that under physiological conditions, the level of melatonin is high during night and is inhibited by daily light to very low levels $[9,108]$. The evening rise in melatonin 
represents an important part of suprachiasmatic-induced adaptation to the rest and activity period [113]. On the other hand, non-dipping patients express a lower nocturnal surge of melatonin release, as reflected by reduced 6-sulfametoxymelatonin in urine [114] and a lower ratio of the night/day concentration of melatonin [115]. Furthermore, experimental pinealectomy in rats reduced both nocturnal and daily melatonin levels [116], as well as the urinary excretion of 6-sulfatoxymelatonin in rats [117]. Additionally, no nocturnal rise in melatonin secretion was observed in pinealectomized patients [118]. Analogically, exposing hamsters to a longer period of continuous light reduced amplitude and shortened duration of enhanced melatonin concentration in the pineal gland and attenuated nocturnal excretion of aMT6s into the urine [119]. This reduction of melatonin secretion was associated with hypertension development in laboratory animals [20].

Thirdly, in the agreement with the proven melatonin deficiency in certain types of hypertension, the supplementation of pinealectomized or continuous light-exposed animals with melatonin prevented hypertension development [120]. In the clinical setting, several weeks of melatonin administration before sleep reduced nocturnal systolic and diastolic BP in non-dipping untreated patients [113], in non-dipping women [87] and in patients with nocturnal hypertension [121]. In agreement with physiological enhancement of melatonin secretion during the night, melatonin should be applied at bedtime. Daytime melatonin intake results in sleepiness and hypothermia during the day [122] and should be avoided [113].

Fourthly, the patho-mechanism of the BP reducing effect of melatonin seems to be unrelated to the well-known effect of melatonin on the quality of sleep. Repeated melatonin intake significantly increases sleep deficiency and actual sleep time and reduces sleep latency. However, although three-week night-time melatonin administration to untreated non-dippers resulted in lowering nigh-time BP levels along with the improvement of sleep, improvement in hemodynamics and sleep were statistically unrelated [113]. Similarly, in young patients with diabetes type 1, melatonin significantly reduced diastolic BP; however, no effect on sleep duration or sleep quality was observed [122].

\section{Questions and Perspectives}

Despite the vast evidence of melatonin's ability to reduce BP and its potential role in BP regulation at the peripheral and central levels, the causative relation of melatonin to the pathogenesis of hypertension development remains controversial. This uncertainty is associated with the variable findings regarding the plasmatic or tissue melatonin profile during hypertension, which may prove to be decreased, normal or even increased.

There is accumulating evidence that the function of the circadian pacemaker in the SCN is deteriorated in essential hypertension. Hypertensive patients show blunted day-night rhythms in sympathetic and parasympathetic heart tone [123]. The levels of neurotransmitters in SCN are significantly reduced, and the SCN output to the sympathetic nervous system is altered in patients with hypertension [124,125]. These changes in the vegetative nervous system may be expected to induce some counter-regulatory mechanisms. Indeed, in untreated hypertensive patients, the morning concentrations of melatonin were higher compared to normotensives, and the level of melatonin was normalized after blood pressure reduction by six-month lacidipine treatment [126]. It has been shown 
in our laboratory that melatonin level in the pineal gland was increased in L-NAME-induced hypertension compared to controls. It was suggested that increased sympathetic tone or reduced NO formation in the PVN in L-NAME-treated rats might have underlain the increased (potentially compensatory) melatonin production. However, in the same experiment, in peripheral organs, melatonin levels were not substantially changed. It has been suggested that increased melatonin production was insufficient to counterbalance the augmented melatonin consumption in the peripheral tissues [42]. Similarly, in rats with chronic immobilization stress and increased sympathetic nerve activity and enhanced circulating norepinephrine levels, the nocturnal melatonin levels were increased [127].

\section{Conclusions}

Although melatonin reduces blood pressure and its deficit seems to be one of the substantial factors in the pathogenesis of hypertension, its production or serum level does not need to be unavoidably reduced in the condition of increased BP. On the contrary, melatonin production can be enhanced along with the augmented sympathetic tone triggering melatonin release, at least in some forms of hypertension. It seems, however, that this supposedly compensatory increase of endogenous melatonin production fails to provide sufficient counter-regulation to the activated autonomic nervous system and can thus be viewed as a "relative" melatonin deficiency.

It is exciting to suppose that artificial light pollution, a general phenomenon of the urbanized world, may be a factor of melatonin level alteration and a risk factor for hypertension development. If inadequate melatonin production may be causally associated with increased nocturnal or even daily BP, improvement of chronodisruption may be a hopeful therapeutic approach. It does not seem unreasonable to suppose that the correction of absolute or relative melatonin deficiency by exogenous melatonin administration may help to attenuate the excessive catecholamine outflow, providing a rational background for therapeutic application of melatonin in hypertension treatment.

\section{Acknowledgments}

This study was elaborated within the Projects APVV-0742-10, VEGA 2/0183/12 and 2/0144/14.

\section{Author Contributions}

Olga Pechanova has a substantial contribution to the conception, design and writing of the paper. Ludovit Paulis contributed importantly on literature search and writing of the paper. Fedor Simko contributed substantially to writing and final approval of the paper.

\section{Conflicts of Interest}

The authors declare no conflict of interest.

\section{References}

1. Paton, J.F.; Waki, H. Is neurogenic hypertension related to vascular inflammation of the brainstem? Neurosci. Biobehav. Rev. 2009, 33, 89-94. 
2. Waki, H.; Gouraud, S.S.; Maeda, M.; Raizada, M.K.; Paton, J.F. Contributions of vascular inflammation in the brainstem for neurogenic hypertension. Respir. Physiol. Neurobiol. 2011, $178,422-428$.

3. Waki, H.; Gouraud, S.S.; Maeda, M.; Paton J.F. Specific inflammatory condition in nucleus tractus solitarii of the SHR: Novel insight for neurogenic hypertension? Auton. Neurosci. 2008, 142, 25-31.

4. Pevet, P.; Challet, E. Melatonin: Both master clock output and internal time-giver in the circadian clocks network. J. Physiol. Paris 2011, 105, 170-182.

5. Hardeland, R.; Cardinali, D.P.; Srinivasan, V.; Spence, D.W.; Brown, G.M.; Pandi-Perumal, S.R. Melatonin-A pleiotropic, orchestrating regulator molecule. Prog. Neurobiol. 2011, 93, 350-384.

6. Reiter, R.J.; Rosales-Corral, S.; Coto-Montes, A.; Boga, J.A.; Tan, D.X.; Davis, J.M.; Konturek, P.C.; Konturek, S.J.; Brzozowski. T. The photoperiod, circadian regulation and chronodisruption: The requisite interplay between the suprachiasmatic nuclei and the pineal and gut melatonin. J. Physiol. Pharmacol. 2011, 62, 269-274.

7. Reiter, R.J.; Tan, D.X.; Rosales-Corral, S.; Manchester, L.C. The universal nature, unequal distribution and antioxidant functions of melatonin and its derivatives. Mini Rev. Med. Chem. 2013, 13, 373-384.

8. Zeman, M.; Herichova, I. Melatonin and clock genes expression in the cardiovascular system. Front. Biosci. 2013, 5, 743-753.

9. Dominguez-Rodriguez, A.; Abreu-Gonzalez, P.; Sanchez-Sanchez, J.J.; Kaski, J.C.; Reiter, R.J. Melatonin and circadian biology in human cardiovascular disease. J. Pineal Res. 2010, 49, 14-22.

10. Dominguez-Rodriguez, A.; Abreu-Gonzalez, P.; Arroyo-Ucar, E., Reiter, R.J. Decreased level of melatonin in serum predicts left ventricular remodelling after acute myocardial infarction. J. Pineal Res. 2012, 53, 319-323.

11. Dominguez-Rodriguez, A.; Abreu-Gonzalez, P.; Reiter, R.J. Melatonin and cardiovascular disease: Myth or reality? Rev. Esp. Cardiol. 2012, 65, 215-218.

12. Reiter, R.J.; Tan, D.X.; Fuentes-Broto, L. Melatonin: A multitasking molecule. Prog. Brain Res. 2010, 181, 127-151.

13. Simko, F.; Paulis, L. Melatonin as a potential antihypertensive treatment. J. Pineal Res. 2007, 42, 319-322.

14. Simko, F.; Pechanova, O. Recent trends in hypertension treatment: Perspectives from animal studies. J. Hypertens. 2009, 27, S1-S4.

15. Tan, D.X.; Hardeland, R.; Manchester, L.C.; Rosales-Corral, S.; Coto-Montes, A.; Boga, J.A.; Reiter, R.J. Emergence of naturally occurring melatonin isomers and their proposed nomenclature. J. Pineal Res. 2012, 53, 113-121.

16. Galano, A.; Tan, D.X.; Reiter, R.J. On the free radical scavenging activities of melatonin's metabolites, AFMK and AMK. J. Pineal Res. 2013, 54, 245-257.

17. Agil, A.; Reiter, R.J.; Jiménez-Aranda, A.; Ibán-Arias, R.; Navarro-Alarcón, M.; Marchal, J.A.; Adem, A.; Fernández-Vázquez G. Melatonin ameliorates low-grade inflammation and oxidative stress in young Zucker diabetic fatty rats. J. Pineal Res. 2013, 54, 381-388. 
18. Venegas, C.; García, J.A.; Doerrier, C.; Volt, H.; Escames, G.; López, L.C.; Reiter, R.J.; Acuña-Castroviejo, D. Analysis of the daily changes of melatonin receptors in the rat liver. J. Pineal Res. 2013, 54, 313-321.

19. Simko, F.; Paulis, L. Antifibrotic effect of melatonin-perspective protection in hypertensive heart disease. Int. J. Cardiol. 2013, 168, 2876-2877.

20. Simko, F.; Reiter, R.J.; Pechanova, O.; Paulis, L. Experimental models of melatonin-deficient hypertension. Front. Biosci. 2013, 18, 616-625.

21. Favero, G.; Rodella, L.F.; Reiter, R.J.; Rezzani, R. Melatonin and its atheroprotective effects: A review. Mol. Cell. Endocrinol. 2014, 382, 926-937.

22. Rosen, J.; Than, N.N.; Koch, D.; Poeggeler, B.; Laatsch, H.; Hardeland, R. Interactions of melatonin and its metabolites with the ABTS cation radical: Extension of the radical scavenger cascade and formation of a novel class of oxidation products, $\mathrm{C} 2$-substituted 3-indolinones. J. Pineal Res. 2006, 41, 374-381.

23. Alonso-Alconada, D.; Alvarez, A.; Arteaga, O.; Martínez-Ibargüen, A.; Hilario, E. Neuroprotective effect of melatonin: A novel therapy against perinatal hypoxia-ischemia. Int. J. Mol. Sci. 2013, 14, 9379-9395.

24. Acuna-Castroviejo, D.; Martin, M.; Macias, M.; Escames, G.; Leon, J.; Khaldy, H.; Reiter, R.J. Melatonin, mitochondria, and cellular bioenergetics. J. Pineal Res. 2001, 30, 65-74.

25. Tomas-Zapico, C.; Coto-Montes, A. A proposed mechanism to explain the stimulatory effect of melatonin on antioxidative enzymes. J. Pineal Res. 2005, 39, 99-104.

26. Reiter, R.J.; Tan, D.X.; Osuna, C.; Gitto, E. Actions of melatonin in the reduction of oxidative stress. A review. J. Biomed. Sci. 2000, 7, 444-458.

27. Kojsova, S.; Jendekova, L.; Zicha, J.; Kunes, J.; Andriantsitohaina, R.; Pechanova, O. The effect of different antioxidants on nitric oxide production in hypertensive rats. Physiol. Res. 2006, 55, S3-S16.

28. Pechanova, O.; Simko, F. Chronic antioxidant therapy fails to ameliorate hypertension: Potential mechanisms behind. J. Hypertens. Suppl. 2009, 27, S32-S36.

29. Paulis, L.; Simko, F.; Laudon, M. Cardiovascular effects of melatonin receptor agonists. Expert Opin. Investig. Drugs 2012, 21, 1661-1678.

30. Slominski, R.M.; Reiter, R.J.; Schlabritz-Loutsevitch, N.; Ostrom, R.S.; Slominski, A.T. Melatonin membrane receptors in peripheral tissues: Distribution and functions. Mol. Cell. Endocrinol. 2012, 351, 152-166.

31. Nosjean, O.; Ferro, M.; Coge, F.; Beauverger, P.; Henlin, J.M.; Lefoulon, F.; Fauchere, J.L.; Delagrange, P.; Canet, E.; Boutin, J.A. Identification of the melatonin-binding site MT3 as the quinone reductase 2. J. Biol. Chem. 2000, 275, 31311-31317.

32. Nosjean, O.; Nicolas, J.P.; Klupsch, F.; Delagrange, P.; Canet, E.; Boutin, J.A. Comparative pharmacological studies of melatonin receptors: MT1, MT2 and MT3/QR2. Tissue distribution of MT3/QR2. Biochem. Pharmacol. 2001, 61, 1369-1379.

33. Luchetti, F.; Canonico, B.; Betti, M.; Arcangeletti, M.; Pilolli, F.; Piroddi, M.; Canesi, L.; Papa, S.; Galli, F. Melatonin signaling and cell protection function. FASEB J. 2010, 24, 3603-3624. 
34. Krause, D.N.; Barrios, V.E.; Duckles, S.P. Melatonin receptors mediate potentiation of contractile responses to adrenergic nerve stimulation in rat caudal artery. Eur. J. Pharmacol. 1995, 276, 207-213.

35. Ting, K.N.; Dunn, W.R.; Davies, D.J.; Sugden, D.; Delagrange, P.; Guardiola-Lemaître, B.; Scalbert, E.; Wilson, V.G. Studies on the vasoconstrictor action of melatonin and putative melatonin receptor ligands in the tail artery of juvenile Wistar rats. Br. J. Pharmacol. 1997, 122, 1299-1306.

36. Girouard, H.; Chulak, C.H.; Lejossec, M.; Lamontagne, D.; de Champlain, J. Vasorelaxant effects of the chronic treatment with melatonin on mesenteric artery and aorta of spontaneously hypertensive rats. J. Hypertens. 2001, 19, 1369-1377.

37. Weekley, L.B. Melatonin-induced relaxation of rat aorta: Interaction with adrenergic agonists. J. Pineal Res. 1991, 11, 28-34.

38. Paulis, L.; Simko, F. Blood pressure modulation and cardiovascular protection by melatonin: Potential mechanisms behind. Physiol. Res. 2007, 56, 671-684.

39. Lusardi, P.; Piazza, E.; Fogari, R. Cardiovascular effects of melatonin in hypertensive patients well controlled by nifedipine: A 24-h study. Br. J. Clin. Pharmacol. 2000, 49, 423-427.

40. Nelson, C.S.; Marino, J.L.; Allen, C.N. Melatonin receptors activate heteromeric G-protein coupled Kir3 channels. Neuroreport 1996, 7, 717-720.

41. Vanecek, J.; Klein, D.C. Sodium-dependent effects of melatonin on membrane potential of neonatal rat pituitary cells. Endocrinology 1992, 131, 939-946.

42. Benova, M.; Herichova, I.; Stebelova, K.; Paulis, L.; Krajcirovicova, K.; Simko, F.; Zeman, M. Effect of L-NAME-induced hypertension on melatonin receptors and melatonin evels in the pineal gland and the peripheral organs of rats. Hypertens. Res. 2009, 32, 242-247.

43. Schepelmann, M.; Molcan, L.; Uhrova, H.; Zeman, M.; Ellinger, I. The presence and localization of melatonin receptors in the rat aorta. Cell. Mol. Neurobiol. 2011, 31, 1257-1265.

44. Barta, A.; Parohova, J.; Vranková, S.; Janega, P.; Kovacsova, M.; Pechanova, O. The effects of melatonin on morphology of cardiovascular system in experimental metabolic syndrome. In Circulation, Proceedings of World Congress of Cardiology Scientific Sessions, Dubai, United Arab Emirates, 18-21 April 2012; Volume 125, p. E913.

45. Masana, M.I.; Doolen, S.; Ersahin, C.; Al-Ghoul, W.M.; Duckles, S.P.; Dubocovich, M.L.; Krause, D.N. MT2 melatonin receptors are present and functional in rat caudal artery. J. Pharmacol. Exp. Ther. 2002, 302, 1295-1302.

46. Tunstall, R.R.; Shukla, P.; Grazul-Bilska, A.; Sun, C.; O’Rourke, S.T. MT2 receptors mediate the inhibitory effects of melatonin on nitric oxide-induced relaxation of porcine isolated coronary arteries. J. Pharmacol. Exp. Ther. 2011, 336, 127-133.

47. Yang, Q.; Scalbert, E.; Delagrange, P.; Vanhoutte, P.M.; O’Rourke, S.T. Melatonin potentiates contractile responses to serotonin in isolated porcine coronary arteries. Am. J. Physiol. Heart Circ. Physiol. 2001, 280, H76-H82.

48. Malpaux, B.; Migaud, M.; Tricoire, H.; Chemineau, P. Biology of mammalian photoperiodism and the critical role of the pineal gland and melatonin. J. Biol. Rhythms 2001, 16, 336-347.

49. Vaněcek, J.; Janský, L. Short days induce changes in specific melatonin binding in hamster median eminence and anterior pituitary. Brain Res. 1989, 477, 387-390. 
50. Duncan, M.J.; Takahashi, J.S.; Dubocovich, M.L. Characteristics and autoradiographic localization of 2-[ $\left.{ }^{125} \mathrm{I}\right]$ iodomelatonin binding sites in Djungarian hamster brain. Endocrinology 1989, 125, 1011-1018.

51. Williams, L.M.; Hannah, L.T.; Hastings, M.H.; Maywood, E.S. Melatonin receptors in the rat brain and pituitary. J. Pineal Res. 1995, 19, 173-177.

52. Menendez-Pelaez, A.; Reiter, R.J. Distribution of melatonin in mammalian tissues: The relative importance of nuclear versus cytosolic localization. J. Pineal Res. 1993, 15, 59-69.

53. Benitez-King, G.; Anton-Tay, F. Calmodulin mediates melatonin cytoskeletal effects. Experientia 1993, 49, 635-641.

54. Pandi-Perumal, S.R.; Trakht, I.; Srinivasan, V.; Spence, D.W.; Maestroni, G.J.; Zisapel, N.; Cardinali, D.P. Physiological effects of melatonin: Role of melatonin receptors and signal transduction pathways. Prog. Neurobiol. 2008, 85, 335-353.

55. Pechanova, O.; Zicha, J.; Paulis, L.; Zenebe, W.; Dobesova, Z.; Kojsova, S.; Jendekova, L.; Sladkova, M.; Dovinova, I.; Simko, F.; et al. The effect of $N$-acetylcysteine and melatonin in adult spontaneously hypertensive rats with established hypertension. Eur. J. Pharmacol. 2007, 561, 129-136.

56. Paulis, L.; Pechanova, O.; Zicha, J.; Barta, A.; Gardlik, R.; Celec, P.; Kunes, J.; Simko, F. Melatonin interactions with blood pressure and vascular function during L-NAME-induced hypertension. J. Pineal Res. 2010, 48, 102-108.

57. Paulis, L.; Pechanova, O.; Zicha, J.; Liskova, S.; Celec, P.; Mullerova, M.; Kollar, J.; Behuliak, M.; Kunes, J.; Adamcova, M.; et al. Melatonin improves the restoration of endothelium-derived constricting factor signalling and inner diameter in the rat femoral artery after cessation of L-NAME treatment. J. Hypertens. 2010, 28, S19-S24.

58. Simko, F.; Pechanova, O.; Pelouch, V.; Krajcirovicova, K.; Mullerova, M.; Bednarova, K.; Adamcova, M.; Paulis, L. Effect of melatonin, captopril, spironolactone and simvastatin on blood pressure and left ventricular remodelling in spontaneously hypertensive rats. J. Hypertens. 2009, 27, S5-S10.

59. Simko, F.; Pechanova, O.; Pelouch, V.; Krajcirovicova, K.; Celec, P.; Palffy, R.; Bednarova, K.; Vrankova, S.; Adamcova, M.; Paulis, L. Continuous light and L-NAME-induced left ventricular remodelling: Different protection with melatonin and captopril. J. Hypertens. 2010, 28, S13-S18.

60. Koziróg, M.; Poliwczak, A.R.; Duchnowicz, P.; Koter-Michalak, M.; Sikora, J.; Broncel, M. Melatonin treatment improves blood pressure, lipid profile, and parameters of oxidative stress in patients with metabolic syndrome. J. Pineal Res. 2011, 50, 261-266.

61. Tan, D.X.; Manchester, L.C.; Reiter, R.J.; Qi, W.; Kim, S.J.; El-Sokkary, G.H. Ischemia/reperfusion-induced arrhythmias in the isolated rat heart: Prevention by melatonin. J. Pineal Res. 1998, 25, 184-191.

62. Tan, D.X.; Manchester, L.C.; Terron, M.P.; Flores, L.J.; Reiter, R.J. One molecule, many derivatives: A never-ending interaction of melatonin with reactive oxygen and nitrogen species? J. Pineal Res. 2007, 42, 28-42.

63. Tan, D.X.; Manchester, L.C.; Reiter, R.J.; Qi, W.B.; Karbownik, M.; Calvo, J.R. Significance of melatonin in antioxidative defense system: Reactions and products. Biol. Signals Recept. 2000, 9 , 137-159. 
64. Reiter, R.J.; Tan, D.X.; Jou, M.J.; Korkmaz, A.; Manchester, L.C.; Paredes, S.D. Biogenic amines in the reduction of oxidative stress: Melatonin and its metabolites. Neuro Endocrinol. Lett. 2008, 29, 391-398.

65. Van Marke de Lumen, K.; Kedziora-Kornatowska, K.; Czuczejko, J.; Szewczyk-Golec, K.; Pawluk, H.; Motyl, J.; Kornatowski, T.; Kedziora, J. Time dependent effect of melatonin administration on lipid peroxidation, superoxide dismutase activity and melatonin concentration in the elderly patients with essential arterial hypertension. Przegl. Lek. 2008, 65, 273-276.

66. Tamura, E.K.; Cecon, E.; Monteiro, A.W.; Silva, C.L.; Markus, R.P. Melatonin inhibits LPS-induced NO production in rat endothelial cells. J. Pineal Res. 2009, 46, 268-274.

67. Wurtman, R.J.; Axelord, J.; Chu, E.W. The relation between melatonin, a pineal substance, and the effects of light on the rat gonad. Ann. N. Y. Acad. Sci. 1964, 117, 228-230.

68. Moore, R.Y. Neural control of the pineal gland. Behav. Brain Res. 1996, 73, 125-130.

69. Dubocovich, M.L.; Cardinali, D.P.; Guardiola-Lemaitre, B.; Hagan, R.M.; Krause, D.N.; Sugden, D.; Vanhoutte, P.M.; Yocca, F.D. Melatonin receptors. In The IUPHAR Compendium of Receptor Characterization and Classification; Media: London, UK, 1998; pp. 187-193.

70. Kalsbeek, A.; Garidou, M.L.; Palm, I.F.; van Der Vliet, J.; Simonneaux, V.; Pevet, P.; Buijs, R.M. Melatonin sees the light: Blocking GABA-ergic transmission in the paraventricular nucleus induces daytime secretion of melatonin. Eur. J. Neurosci. 2000, 12, 3146-3154.

71. Klein, D.C.; Sugden, D.; Weller, J.L. Postsynaptic alpha-adrenergic receptors potentiate the $\beta$-adrenergic stimulation of pineal serotonin $N$-acetyltransferase. Proc. Natl. Acad. Sci. USA 1983, 80, 599-603.

72. Reiter, R.J. Pineal melatonin: Cell biology of its synthesis and of its physiological interactions. Endocr. Rev. 1991, 12, 151-180.

73. Ribelayga, C.; Pevet, P.; Simonneaux, V. Adrenergic and peptidergic regulations of hydroxyindole- $O$-methyltransferase activity in rat pineal gland. Brain Res. 1997, 777, 247-501.

74. Schomerus, C.; Korf, H.W. Mechanisms regulating melatonin synthesis in the mammalian pineal organ. Ann. N. Y. Acad. Sci. 2005, 1057, 372-383.

75. Cecon, E.; Fernandes, P.A.; Pinato, L.; Ferreira, Z.S.; Markus, R.P. Daily variation of constitutively activated nuclear factor kappa B (NFKB) in rat pineal gland. Chronobiol. Int. 2010, 27, 52-67.

76. Wang, M.; Yokotani, K.; Nakamura, K.; Murakami, Y.; Okada, S.; Osumi, Y. Melatonin inhibits the central sympatho-adrenomedullary outflow in rats. Jpn. J. Pharmacol. 1999, 81, 29-33.

77. K-Laflamme, A.; Wu, L.; Foucart, S.; de Champlain, J. Impaired basal sympathetic tone and $\alpha 1$-adrenergic responsiveness in association with the hypotensive effect of melatonin in spontaneously hypertensive rats. Am. J. Hypertens. 1998, 11, 219-229.

78. Chuang, J.I.; Chen, S.S.; Lin, M.T. Melatonin decreases brain serotonin release, arterial pressure and heart rate in rats. Pharmacology 1993, 47, 91-97.

79. Girouard, H.; Chulak, C.H.; Lejossec, M.; Lamontagne, D.; de Champlain, J. Chronic antioxidant treatment improves sympathetic functions and $\beta$-adrenergic pathway in the spontaneously hypertensive rats. J. Hypertens. 2003, 21, 179-188. 
80. Girouard, H.; Denault, C.; Chulak, C.; de Champlain, J. Treatment by $N$-acetylcysteine and melatonin increases cardiac baroreflex and improves antioxidant reserve. Am. J. Hypertens. 2004, 17, 947-954.

81. Arangino, S.; Cagnacci, A.; Angiolucci, M.; Vacca, A.M.; Longu, G.; Volpe, A.; Melis, G.B. Effects of melatonin on vascular reactivity, catecholamine levels, and blood pressure in healthy men. Am. J. Cardiol. 1999, 83, 1417-1419.

82. Yildiz, M.; Sahin, B.; Sahin, A. Acute effects of oral melatonin administration on arterial distensibility, as determined by carotid-femoral pulse wave velocity, in healthy young men. Exp. Clin. Cardiol. 2006, 11, 311-313.

83. Tengattini, S.; Reiter, R.J.; Tan, D.X.; Terron, M.P.; Rodella, L.F.; Rezzani, R. Cardiovascular diseases: Protective effects of melatonin. J. Pineal Res. 2008, 44, 16-25.

84. Simko, F.; Pechanova, O. Potential roles of melatonin and chronotherapy among the new trends in hypertension treatment. J. Pineal Res. 2009, 47, 127-133.

85. Cardinali, D.P.; Srinivasan, V.; Brzezinski, A.; Brown, G.M. Melatonin and its analogs in insomnia and depression. J. Pineal Res. 2012, 52, 365-375.

86. Paulis, L.; Pechanova, O.; Zicha, J.; Krajcirovicova, K.; Barta, A.; Pelouch, V.; Adamcova, M.; Simko, F. Melatonin prevents fibrosis but not hypertrophy development in the left ventricle of $\mathrm{N}^{\mathrm{G}}$-nitro-L-arginine-methyl ester hypertensive rats. J. Hypertens. Suppl. 2009, 27, S11-S16.

87. Cagnacci, A.; Cannoletta, M.; Renzi, A.; Baldassari, F.; Arangino, S.; Volpe, A. Prolonged melatonin administration decreases nocturnal blood pressure in women. Am. J. Hypertens. 2005, $18,1614-1618$.

88. Reppert, S.M.; Weaver, D.R.; Rivkees, S.A.; Stopa, E.G. Putative melatonin receptors in a human biological clock. Science. 1988, 242, 78-81.

89. Patel, K.P.; Li, Y.F.; Hiroka, Y. Role of nitric oxide in central sympathetic outflow. Exp. Biol. Med. 2001, 226, 814-824.

90. Wang, F.; Li, J.; Wu, C.; Yang, J.; Xu, F.; Zhao, Q. The GABAA receptor mediates the hypnotic activity of melatonin in rats. Pharmacol. Biochem. Behav. 2003, 74, 573-578.

91. Rossi, N.F.; Black, S.M.; Telemaque-Potts, S.; Chen, H. Neuronal nitric oxide synthase activity in the paraventricular nucleus buffers central endothelin-1- induced pressor response and vasopressin secretion. J. Cardiovasc. Pharmacol. 2004, 44, S283-S288.

92. Irmak, M.K.; Sizlan, A. Essential hypertension seems to result from melatonin-induced epigenetic modifications in area postrema. Med. Hypotheses. 2006, 66, 1000-1007.

93. Xia, C.M.; Shao, C.H.; Xin, L.; Wang, Y.R.; Ding, C.N.; Wang, J.; Shen, L.L.; Li, L.; Cao, Y.X.; Zhu, D.N. Effects of melatonin on blood pressure in stress-induced hypertension in rats. Clin. Exp. Pharmacol. Physiol. 2008, 35, 1258-1264.

94. Li, H.L.; Kang, Y.M.; Yu, L.; Xu, H.Y.; Zhao, H. Melatonin reduces blood pressure in rats with stress-induced hypertension via GABAA receptors. Clin. Exp. Pharmacol. Physiol. 2009, 36, 436-440.

95. Witte, K.; Schnecko, A.; Buijs, R.M.; van der Vliet, J.; Scalbert, E.; Delagrange, P.; Guardiola-Lemaître, B.; Lemmer, B. Effects of SCN lesions on circadian blood pressure rhythm in normotensive and transgenic hypertensive rats. Chronobiol. Int. 1998, 15, 135-145. 
96. Zeman, M.; Szantoova, K.; Stebelova, K.; Mravec, B.; Herichova, I. Effect of rhythmic melatonin administration on clock gene expression in the suprachiasmatic nucleus and the heart of hypertensive TGR(mRen2)27 rats. J. Hypertens. 2009, 27, S21-S26.

97. Lau, F.C.; Shukitt-Hale, B.; Joseph, J.A. The beneficial effects of fruit polyphenols on brain aging. Neurobiol. Aging 2005, 26, 128-132.

98. Kotler, M.; Rodríguez, C.; Sáinz, R.M.; Antolín, I.; Menéndez-Peláez, A. Melatonin increases gene expression for antioxidant enzymes in rat brain cortex. J. Pineal Res. 1998, 24, 83-89.

99. Zhou, J.; Zhang, S.; Zhao, X.; Wei, T. Melatonin impairs NADPH oxidase assembly and decreases superoxide anion production in microglia exposed to amyloid- $\beta 1-42$. J. Pineal Res. 2008, 45, 157-165.

100. Haulică, I. Experimental evidence on pineal renin-angiotensin system as activator of serotonin and melatonin synthesis. Rev. Med. Chir. Soc. Med. Nat. Iasi. 1991, 95, 293-296.

101. Carrera, M.P.; Ramírez-Expósito, M.J.; Valenzuela, M.T.; Dueñas, B.; García, M.J.; Mayas, M.D.; Martínez-Martos, J.M. Renin-angiotensin system-regulating aminopeptidase activities are modified in the pineal gland of rats with breast cancer induced by -methyl-nitrosourea. Cancer Investig. 2006, 24, 149-153.

102. Mohan, N.; Sadeghi, K.; Reiter, R.J.; Meltz, M.L. The neurohormone melatonin inhibits cytokine, mitogen and ionizing radiation induced NF-кB. Biochem. Mol. Biol. Int. 1995, 37, 1063-1070.

103. Reiter, R.J.; Calvo, J.R.; Karbownik, M.; Qi, W.; Tan, D.X. Melatonin and its relation to the immune system and inflammation. Ann. N. Y. Acad. Sci. 2000, 917, 376-386.

104. Mauriz, J.L.; Collado, P.S.; Veneroso, C.; Reiter, R.J.; González-Gallego, J. A review of the molecular aspects of melatonin's anti-inflammatory actions: Recent insights and new perspectives. J. Pineal Res. 2013, 54, 1-14.

105. Pozo, D.; Reiter, R.J.; Calvo, J.R.; Guerrero, J.M. Inhibition of cerebellar nitric oxide synthase and cyclic GMP production by melatonin via complex formation with calmodulin. J. Cell. Biochem. 1997, 65, 430-442.

106. Koh, P.O. Melatonin regulates nitric oxide synthase expression in ischemic brain injury. J. Vet. Med. Sci. 2008, 70, 747-750.

107. Tain, Y.L.; Leu, S.; Wu, K.L.; Lee, W.C.; Chan, J.Y. Melatonin prevents maternal fructose intake-induced programmed hypertension in the offspring: Roles of nitric oxide and arachidonic acid metabolites. J. Pineal Res. 2014, 57, 80-89.

108. Reiter, R.J; Tan, D.X; Korkmaz, A. The circadian melatonin rhythm and its modulation: Possible impact on hypertension. J. Hypertens. Suppl. 2009, 27, S17-S20.

109. White, W.B. Relating cardiovascular risk to out-of-office blood pressure and the importance of controlling blood pressure 24 hours a day. Am. J. Med. 2008, 121, S2-S7.

110. Ohkubo, T.; Imai, Y.; Tsuji, I.; Nagai, K.; Watanabe, N.; Minami, N.; Kato, J.; Kikuchi, N.; Nishiyama, A.; Aihara, A.; et al. Relation between nocturnal decline in blood pressure and mortality. The Ohasama Study. Am. J. Hypertens. 1997, 11, 1201-1207.

111. Hermida, R.C.; Ayala, D.E.; Mojón, A.; Fernández, J.R. Decreasing sleep-time blood pressure determined by ambulatory monitoring reduces cardiovascular risk. J. Am. Coll. Cardiol. 2011, $58,1165-1173$. 
112. Hermida, R.C.; Ayala, D.E.; Mojón, A.; Fernández, J.R. Influence of circadian time of hypertension treatment on cardiovascular risk: Results of the MAPEC study. Chronobiol. Int. 2010, 27, 1629-1651.

113. Scheer, F.A.; van Montfrans, G.A.; van Someren, E.J.; Mairuhu, G.; Buijs, R.M. Daily nighttime melatonin reduces blood pressure in male patients with essential hypertension. Hypertension 2004, 43, 192-197.

114. Jonas, M.; Garfinkel, D.; Zisapel, N.; Laudon, M.; Grossman, E. Impaired nocturnal melatonin secretion in non-dipper hypertensive patients. Blood Press 2003, 12, 19-24.

115. Zeman, M.; Dulková, K.; Bada, V.; Herichová, I. Plasma melatonin concentrations in hypertensive patients with the dipping and non-dipping blood pressure profile. Life Sci. 2005, 76, 1795-1803.

116. Holmes, S.W.; Sugden, D. Proceedings: The effect of melatonin on pinealectomy-induced hypertension in the rat. Br. J. Pharmacol. 1976, 56, 360P-361P.

117. Brown, G.M.; Bar-Or, A.; Grossi, D.; Kashur, S.; Johannson, E.; Yie, S.M. Urinary 6-sulphatoxymelatonin, an index of pineal function in the rat. J. Pineal Res. 1991, 10, 141-147.

118. Chik, C.L.; Talalla, A.; Brown, G.M. Effect of pinealectomy on serum melatonin, luteinizing hormone and prolactin: A case report. Clin. Endocrinol. 1985, 23, 367-372.

119. Stieglitz, A.; Spiegelhalter, F.; Klante, G.; Heldmaier, G. Urinary 6-sulphatoxymelatonin excretion reflects pineal melatonin secretion in the Djungarian hamster (Phodopus sungorus). J. Pineal Res. 1995, 18, 69-76.

120. Simko, F.; Pechanova, O.; Repova Bednarova, K.; Krajcirovicova, K.; Celec, P.; Kamodyova, N.; Zorad, S.; Kucharska, J.; Gvozdjakova, A.; Adamcova, M.; et al. Hypertension and cardiovascular remodelling in rats exposed to continuous light: Protection by ACE-inhibition and melatonin. Mediators Inflamm. 2014, 2014, 703175.

121. Grossman, E.; Laudon, M.; Yalcin, R.; Zengil, H.; Peleg, E.; Sharabi, Y.; Kamari, Y.; Shen-Orr, Z.; Zisapel, N. Melatonin reduces night blood pressure in patients with nocturnal hypertension. Am. J. Med. 2006, 119, 898-902.

122. Cagnacci, A.; Elliott, J.A.; Yen, S.S. Melatonin: A major regulator of the circadian rhythm of core temperature in humans. J. Clin. Endocrinol. Metab. 1992, 75, 447-452.

123. Nakano, Y.; Oshima, T.; Ozono, R.; Higashi, Y.; Sasaki, S.; Matsumoto, T.; Matsuura, H.; Chayama, K.; Kambe, M. Non-dipper phenomenon in essential hypertension is related to blunted nocturnal rise and fall of sympatho-vagal nervous activity and progress in retinopathy. Auton. Neurosci. 2001, 88, 181-186.

124. Goncharuk, V.D.; van Heerikhuize, J.; Dai, J.P.; Swaab, D.F.; Buijs, R.M. Neuropeptide changes in the suprachiasmatic nucleus in primary hypertension indicate functional impairment of the biological clock. J. Comp. Neurol. 2001, 431, 320-330.

125. Goncharuk, V.D.; van Heerikhuize, J.; Swaab, D.F.; Buijs, R.M. Paraventricular nucleus of the human hypothalamus in primary hypertension: Activation of corticotropin-releasing hormone neurons. J. Comp. Neurol. 2002, 443, 321-331. 
126. Escames, G.; Khaldy, H.; León, J.; González, L.; Acuña-Castroviejo, D. Changes in iNOS activity, oxidative stress and melatonin levels in hypertensive patients treated with lacidipine. J. Hypertens. 2004, 22, 629-635

127. Dagnino-Subiabre, A.; Orellana, J.A.; Carmona-Fontaine, C.; Montiel, J.; Díaz-Velíz, G.; Serón-Ferré, M.; Wyneken, U.; Concha, M.L.; Aboitiz, F. Chronic stress decreases the expression of sympathetic markers in the pineal gland and increases plasma melatonin concentration in rats. J. Neurochem. 2006, 97, 1279-1287

(C) 2014 by the authors; licensee MDPI, Basel, Switzerland. This article is an open access article distributed under the terms and conditions of the Creative Commons Attribution license (http://creativecommons.org/licenses/by/4.0/). 